\title{
30 years of sunflower breeding in France
}

Oléagineux, Corps Gras, Lipides. Volume 10, Numéro 1, 66-73, Janvier - Février 2003, Fondamental

Auteur(s) : Felicity VEAR, Henri BONY, Georges JOUBERT, Denis TOURVIEILLE de LABROUHE, Isabelle PAUCHET, Xavier PINOCHET, INRA, U.M.R. INRA-UBP "Amélioration et Santé des Plantes", 234 av. du Brézet, 63039 Clermont-Ferrand cedex 2, France.

Résumé : Les rendements et les résistances aux maladies de 4 groupes de 5 variétés de tournesol correspondant aux génotypes les plus cultivés en France depuis 1965 ont été comparés sur deux années d'expérimentation : 25 essais "rendements" et 7 essais "maladies". Les observations ont montré un gain moyen de rendement en grain de $40 \%$ pour les 5 variétés cultivées après 1995 par rapport aux 5 variétés cultivées avant 1975, soit une progression moyenne de $33 \mathrm{~kg} / \mathrm{ha}$ (ou 1,3\%) par an, avec une accélération marquée pour les dernières années. L'augmentation du rendement huilier (50 \%) est essentiellement due, à partir de 1980, au gain de rendement en grain; en effet, la teneur en huile reste stable depuis cette date. Les niveaux de précocité et les tailles sont, en moyenne, les mêmes depuis 30 ans. Par contre les variétés actuelles sont nettement moins sensibles à la verse et aux maladies : réduction de la sensibilité à la verse de $80 \%$, aux attaques de Sclerotinia sur capitule de $60 \%$ et de $30 \%$ pour les attaques de Phomopsis sur tige. Pendant la première décennie, l'augmentation du rendement est liée à une forte augmentation du nombre de grains à l'hectare. Au contraire, nous observons une augmentation significative du poids de 1000 grains durant la dernière décennie. Sept essais "rendement" ont été touchés par des attaques parasitaires non négligeables, ce qui a permis de montrer que $25 \%$ de l'augmentation du rendement pouvait être expliqué par une augmentation de la résistance à Sclerotinia ou au phomopsis. Ce sont dans les conditions pédoclimatiques du Centre de la France qui donnent de forts potentiels de rendement mais des risques d'attaques parasitaires importants, que les variétés récentes expriment pleinement leur haut niveau de productivité. Les auteurs concluent que, dans un contexte d'une politique agricole soutenant cette espèce, les variétés modernes devraient être adaptées aux régions à fort rendement.

Mots-clés : Helianthus annuus, hybride, rendement, résistance aux maladies, progrès génétique.

Keywords : Helianthus annuus, hybrid, yield, disease resistance, genetic gain.

\section{ARTICLE}

Introduction

Until 1960, sunflowers were grown in France only for bird feed, but with the introduction of Russian open pollinated varieties containing up to $45 \%$ oil in the seed, use as an oil crop developed. Sunflowers have been bred in France since 1962, with the first hybrid in the world (INRA6501) registered by INRA in 1969. This and other hybrids registered in the next five years, used genic male 
sterility [1] to ensure cross pollination between parental lines. The first hybrid using cytoplasmic male sterility [2], Relax, was registered in 1974. This male sterility was distributed freely and private breeding firms throughout the world became interested in hybrid sunflowers. In France, many firms started breeding programmes in the period from 1972 to 1980, and breeding effort has been continuous.

Sunflowers were a particularly profitable crop from 1980 to 1992, second only to sugar beet [3]. However, since the change in the Common Agricultural Policy of the European Union in 1992, oil crops have become generally less profitable than cereals and sunflowers are no longer grown on the most fertile soils, where, in addition, irrigation is most often possible. Figure 1 shows that, although the trend in national mean yield is still positive, there has been a short term stagnation, and this led to the suggestion that there had been no real genetic improvement recently. To determine the true position, INRA, CETIOM, the breeders belonging to the association AMSOL and some interested farmers (Astria group) carried out a series of trials in the major regions of France where sunflowers are grown, in 2000 and 2001. These trials covered the range of cropping practices now used for sunflowers in France and permitted comparison in the same conditions of the varieties most widely grown at different periods since 1970 . The results are presented here together with analyses which show the characters for which breeding programmes have given significant improvements and possible future developments.

Materials and Methods

\section{Sunflower varieties}

Twenty varieties were chosen by INRA and CETIOM as representing the French sunflower crop over the last 30 years. Four groups of five varieties were made up to represent those grown in the periods 1965-75, 1975-85, 1985-95 and 1995-2000. The varieties are presented in table 1. Most of them were chosen because they were very widely grown for a number of years; each group covering $80 \%$ or more of the area grown to sunflowers during the period concerned. However, a few were chosen because of specific interest: Vidoc appeared to be a good early variety when registered, but then showed considerable disease susceptibility which halted its career in France although it was grown in countries with less disease problems; Euroflor was not very widely grown because it was later than other varieties, but its yield was unbeaten when it was a check for registration trails; HeliasolRM was chosen as a modern variety with a high oil content, to avoid the recent group being made up of rather similar genotypes.

For all the varieties not in current production, hybrid seed was produced in isolated plots or netting cages in 1999 from the inbred lines which are maintained by the breeders. All the varieties received the same seed treatment, in particular metalaxyl, in order to protect against downy mildew, especially the older varieties which are resistant to few or none of the races now present in France. 
Trial organisation

The locations of the trials in 2000 and 2001 are presented in figure 2.

In 2000, results were obtained from 18 yield trials, covering the main regions of France where sunflowers are grown: Loire valley and Central France, Poitou-Charentes (Atlantic coast) and South West France (around Toulouse). In each case, there were 2 replications of about 100 plants. In 2001, 8 trials of the same size were carried out, also in different parts of France, but with more trials on lighter soils and hill slopes than in 2000.

The trials were carried out under the usual agricultural practices for the area in which they were placed. Plant densities were generally 60-70000 plants/ha, but soil preparation, fertilisation, irrigation and anti-Phomopsis spraying varied according to local conditions.

In 2000, sowing dates were later than usual, due to rainfall in April. They varied from March 17th (one trial sown exceptionally early to obtain flowering in June) to May 23rd. The date of $17 / 3$ and then from $11 / 4$ to $25 / 4$ were considered as early sowings, $3 / 5$ to $7 / 5$ as medium and from $13 / 5$ to $23 / 5$ as late. In 2001 early sowing dates were $2 / 4$ to $18 / 4$, medium $26 / 4$ and late, from 10/5 to 22/5.

Observations were made of seed yield (plot fresh seed weight corrected by seed water content, converted to tonnes/ha), \% water content of seed at harvest (generally measured by Dickie-John humidimetre), seed oil content (measured on dry seed by NMR), 1000 seed weight (measured on the sample taken for oil content), plant height (mean per plot), \% lodging (\% of plants with the capitulum touching the ground), \% Sclerotinia sclerotiorum head rot (\% of plants with Sclerotinia lesions on the capitulum at maturity) and \% Phomopsis (Diaporthe helianthi) attack (\% of plants with stem lesions at least $5 \mathrm{~cm}$ long 1 month after flowering). The last 3 observations were made when there was enough attack to give significant differences between varieties.

In addition, in 2000, 7 specific "semi-natural attack" trials were made to determine levels of resistance to Sclerotinia head rot ( 3 trials: DMO0, LMO0, RO00), basal stem rot and terminal bud attack ( 1 trial: RMO0) and to Phomopsis ( 3 trials: ENOO, NPOO, TSO0). In each case there were 2 replications of about 50 plants. Methodology was that used in the official trial for registration of varieties on the French catalogue, with provision of inoculum and irrigation during the infection period $[4,5]$.

Results

Preliminary analyses

Preliminary two-way (variety, block) analyses of variance were made to determine validity of results according to coefficient of variation (cv) and significance of varietal effects (F variety). Phenotypic 
correlations were calculated between the data from each location to check whether there were any unusual results that needed close examination.

Mean yields varied from 1.5 to $4.0 \mathrm{t} / \mathrm{ha}$, with an average of $3.0 \mathrm{t} / \mathrm{ha}$, slightly above the recent national average yield of about $2.5 \mathrm{t} / \mathrm{ha}$, as may be expected for small plot trials. Seed yield was retained for all trials completed (25), with a mean cv of $8.9 \%$ and least significant difference (Isd) of $0.41 \mathrm{t} / \mathrm{ha}$. The greatest cv was $14.7 \%$ (trial SLO0), but this trial was retained because this variability was explained by a very early sowing, and slight attacks by Phomopsis and Sclerotinia and also some lodging. Also, it showed a mean correlation of $r=0.69$ with the other trials

The mean correlation between one trial and all the others was $r=0.70$ (varying from $r=0.78$ to $r=0.38$ according to location). For the 25 series of results, 269 of the 300 possible regressions were highly significant $(P>0.01)$, and 17 others significant $(P>0.05)$. Only 14 comparisons were not significant, related to two locations in 2000 , one from a very late sowing (CSO0) and the other (RG00) generally atypical but, with cv of $10.4 \%$ and $11.7 \%$ respectively, there was no reason to eliminate them from the mean. Correlations between trials in the same location in the two years were generally close (mean $r=0.77$ ), but not closer than some trials in different locations.

Seed water content at harvest, the usual measurement of earliness, was retained for the $14 / 25$ locations with $9-15 \%$ mean water content of the seed in 2000 and $8-13 \%$ in 2001, giving significant differences between varieties. The mean cv was $15.1 \%$, and Isd $2.5 \%$. Oil content (at $9 \%$ water content with $2 \%$ impurities, which is the official French measurement) was retained in all locations where it was measured, with a cv of 2.53 and an Isd of 1.46 points. Oil yield was calculated from seed yield and oil content. Thousand seed weights were measured on four trials in 2000 (cv: 5.65 , Isd: $4.0 \mathrm{~g}$ ). Plant height was measured in 21 locations with a mean cv of $4.2 \%$ and an Isd of $8.7 \mathrm{~cm}$.

Only two trials in 2000 showed significant lodging, but results were well correlated $(r=0.70)$, with significant differences between varieties. Significant levels of Sclerotinia head rot were observed in the three "semi-natural" attack trials and in one yield trial in 2000 (SF00), with a mean of 27.2\%. Correlations between the special trials and the trial with natural attack were highly significant $(r=0.52-0.85)$ so this trial was included in mean Sclerotinia head rot reactions. For Phomopsis, in the three special trials, there was a high frequency of disease (mean 74.5\%), which meant that even the most resistant varieties showed 50 to $60 \%$ attack. These trials were correlated with a mean coefficient of $r=0.70$. Five of the six yield trials showing natural attack in 2000 were included in the disease resistance results, because they covered the range of disease intensities which may be encountered and showed significant differences between varieties. Mean natural attack was $35.6 \%$, with the most resistant varieties showing 10 to $20 \%$ attack and little yield loss. Correlations were significant in $26 / 28$ comparisons with a mean of $r=0.57$. In the one trial specially carried out to measure reaction to Sclerotinia root rot (RMO0), attack was rather irregular, and although a mean of $22 \%$ of plants showed symptoms, there were no significant differences between varieties, so these results are not presented. In this trial, Sclerotinia rot of young leaves, which, in favourable conditions 
may lead to destruction of terminal buds, was observed, with significant differences between varieties. The only variety heavily attacked was Vidoc (89\%), and there were slight attacks on Mirasol (20\%), Melody (23\%) and HeliasolRM (28\%).

Varietal characteristics according to date of registration

Table 2 presents the mean relative value of each variety for each character, compared with the means of the first series of five varieties (Peredovik, INRA6501, Rémil, Airelle and Relax), since the aim of the study was to determine improvement obtained since 1970. The bottom line of the table, the first group mean, presents, for example, mean yields in $\mathrm{t} / \mathrm{ha}$ or mean seed oil contents of this group of 5 varieties over all the trials. Table 3 presents the means of each group of five varieties, compared with the first group, to quantify genetic gain over the years.

For the character seed yield, table 2 shows an increase in yield of the four hybrids with genic male sterility (98.6), compared with the open pollinated variety Peredovik (92.2) and the first hybrid with cytoplasmic male sterility, Relax, at 111.9, could have formed part of the second group. Tables 2 and 3 show quite clearly that there has been continuous improvement in seed yield, from 100 to 139.9, with an acceleration in gain for the varieties registered since 1995. In contrast, for oil content, the first hybrids were not as good as Peredovik, and it was in the second period that there was an increase in oil content to slightly above that of the population variety. Since 1980, the mean oil content of each group of varieties has not increased, and, for the most recent group, slightly declined. Individual varieties have shown progress for oil content, the richest being DK3790 (group 3) and HeliasolRM (group 4), but they are balanced by other improved yield but lower oil content genotypes in these groups. Oil yield was calculated from the combination of grain yield and oil content and shows an increase of almost $50 \%$ over 30 years.

Over the period studied, there has been maintenance of variability for 1000 seed weight, earliness and plant height. Thousand seed weight was generally reduced in the second group of varieties, compared with the first, but has slowly increased more recently to a mean about the size of seed of Peredovik. Similarly, the second group of hybrids were, on average, a little earlier than the first group, and included the earliest variety, Primasol. It may be noted that the recent groups showed a wider range of earliness, 77.8-143.1 for group 3 and 81.4-124.4 for group 4, than for group 1 (92.9107.4). Mean plant height has changed very little, with the widest range among the recent varieties (85.8-109.1).

Thousand seed weight and seed yield were used to calculate relative seed number per $\mathrm{m}^{2}$, and thus, since all varieties were at the same density, the comparative values would be the same for seed number per plant. There has always been a wide variation between varieties in one group, although the smallest numbers of seed were observed for the first group (Peredovik: 84.9, Rémil: 90.8). The largest seed numbers appear in group 3 (DK3790: 163.3, Euroflor: 142.7) and group 2 (Viki: 146.5) as well as in group 4 (LG5660: 151.3, Melody: 144). For the mean values, there was a large increase for the second group of hybrids (129.2) compared with the first (100), but since then there has been little change (group 3:128.2, group 4: 131.0). 
Resistance to lodging and fungal attacks have increased dramatically over the years. Peredovik was quite susceptible to lodging, whereas groups 3 and 4 show very little damage. Sclerotinia head rot on recent varieties was only one third that on the first group. It may be noted that, already, in this first group, and in the second group, there were large differences in reaction (INRA6501: 164, Primasol 198, Rémil 66, Relax 46 and Frankasol 44). In contrast, the third and fourth groups include no highly susceptible varieties (maximum: 72), and some that show significantly improved resistance (Rigasol 10). Phomopsis was first observed in France in 1984, so that breeding effort dates from this time. The first two groups show similar mean reactions, whereas the third and fourth groups, with the exception of Vidoc, show a 30\% improvement in the highly infected trials.

Relative improvements in yield according to cropping conditions

Table 4 presents a classification of trials according to cropping conditions: year, region, mean yield, sowing date and presence or absence of Phomopsis or Sclerotinia. Not all the possible conditions are covered, but the trials represent a wide range of husbandry practises. Table 5 presents comparisons of relative yield in groups of trials with different characteristics, in order to determine whether varieties of different periods were particularly adapted to certain types of conditions. For each comparison except for difference in level of yield/ha, the mean yields of the first group of varieties did not differ significantly between the types of conditions.

There was very little effect of year, all variety groups behaved similarly. The correlation between the mean seed yield for 2000 and 2001 was 0.97, and there was no significant interaction for yield between year and variety. This was also true for plant height $(r=0.91)$ and oil content $(r=0.97)$. There was a slight year-variety interaction for seed water content at harvest although with a close correlation between 2000 and $2001(r=0.87)$, probably because there was a lesser range in humidity in 2001, such that the early varieties appeared less early compared with the mean and the late varieties less late. There were no observations of diseases or PMG in 2001.

The main conditions that affected relative yield was the presence of Sclerotinia and Phomopsis in $7 / 25$ trials. Separate analyses of the series of trials with and without disease shows that part of improved yield is due to increased disease resistance. Group 2 showed $4 \%$ more relative yield under disease conditions compared with absence of disease, group 3 (with the exception of Vidoc), $7.5 \%$ more and group $4,10.8 \%$ more.

The results of the other analyses made probably depend partly on this disease resistance. For sowing date, early sowing gave the best demonstration of improved yields for group 4, whereas this was not the case for the older varieties. The difference between early and intermediate sowing dates was always significant (with disease $t=5.82,83$ degrees of freedom ( $d f$ ); without disease $t=7.58,63 \mathrm{df}$ ), and, in the presence of disease, early sowings were better than late sowing dates ( $t=2.12,73 \mathrm{df})$. In the absence of disease, the better yield gain from early sowings compared with late sowings had a probability of $\mathrm{P}<0.10(\mathrm{t}=1.91,58 \mathrm{df})$. For region, central France gave the best expression of yield 
gain, for all groups of varieties, and Poitou-Charentes the least, perhaps because there no trials were attacked by Sclerotinia or Phomopsis in this last region. South-west France was intermediate.

The trials were also divided into two groups according to their mean yield level: more or less than $3 \mathrm{t} / \mathrm{ha}$. In this case, the trials with lower yields appeared to give best expression of improved yields. This may be true, but it may also be a question of percentage gain: in the lower yielding trials, with a mean of $2.53 \mathrm{t} / \mathrm{ha}$, the first varieties gave $2.07 \mathrm{t} / \mathrm{ha}$ and the recent varieties $3.09 \mathrm{t} / \mathrm{ha}$, whereas in the higher yielding trials, with a mean of $3.58 \mathrm{t} / \mathrm{ha}$, although the percentage gain was less, when the first varieties produced $3.00 \mathrm{t} / \mathrm{ha}$, the recent ones produced $4.19 \mathrm{t} / \mathrm{ha}$.

\section{Discussion}

This study was made to quantify the results of sunflower breeding programmes over 30 years, from a time when this crop was little known, over a period when it was well supported, to the present day, when agricultural politics have somewhat reduced its profitability compared with cereals. The sunflower crop is environmentally of great interest, as part of a rotation with cereals and because it has a small input requirement, in particular concerning pesticides [6, 7]. Future breeding programmes need to maintain interest in this crop, and a study of what has been attained can help in deciding future work.

The 20 varieties chosen represent those that have been most widely grown in France; they do not represent all the types of hybrids registered on the official catalogue, but they were those preferred by farmers at each period, being grown for up to ten years. They were not chosen as advertisements for particular varieties or breeders, the most important conclusions are drawn from the means of each variety group. Overall, there has been a $40 \%$ increase in seed yield and a $50 \%$ increase in oil yield, together with a $80 \%$ reduction in lodging, a $60 \%$ reduction in Sclerotinia head rot and a $30 \%$ reduction in Phomopsis symptoms.

The results show that sunflower is a true cross-pollinated crop showing hybrid vigour, with immediate improvement of seed yields in the first hybrids, compared with the heterogeneous open pollinated variety Peredovik, which was the main variety grown before their introduction. These trials showed that improvements in seed yield were highly significant between all groups, on average $1.3 \%$ ( $33 \mathrm{~kg} / \mathrm{ha}$ ) per year, but with an acceleration of gain in the most recent group: $19.3 \%$ compared with group 3, group 2-1: $12.7 \%$, groups $3-2: 7.4 \%$. Thus, there is no reason to doubt that varieties showing further improvements in yield will be developed. Of course, these results depend on the five varieties chosen to represent the period, but they make it possible to estimate general effects of breeding programmes. This improvement is partly due to improvement in yield per se and partly to disease resistance.

In contrast to seed yield, there has not been a significant general improvement in oil content, except between group 1 (excluding Peredovik) and group 2. This is not because of the difficulty of breeding, oil content is a highly heritable character [8], easy to measure by Nuclear Magnetic Resonance. There 
have been improved varieties, such as DK3790 and HeliasolRM, but two factors have contributed to the development of high yielding but rather low oil genotypes. One is that the varieties richest in oil have generally not been the best yielding, probably because it takes more energy to produce a gram of oil than a gram of cellulose or fibre, and the highest oil yield/ha have been obtained with relatively low oil varieties. Secondly, farmers are not always paid for their oil content, so they prefer varieties with the highest seed yields.

The relative importance of seed yield over oil content can be seen in the variation of yield components over the years. When breeding for oil content was particularly important (group 2), mean seed size showed a reduction, so, to obtain improved yields, the genotypes retained necessarily had greater seed number $/ \mathrm{m}^{2}$. In contrast, in groups 3 and 4 , the average seed number/m\&sup2; stayed stable, and seed size has gradually increased to that of Peredovik. The average for the recent varieties is a seed size and oil content of Peredovik, with $50 \%$ more seeds $/ \mathrm{m}^{2}$. It may be suggested that, since there has been a slight decrease in oil content linked with this increase in seed size, it would be a good thing if future improvements in yield should came from an increase in seed number rather than seed size. Of course, this is true only of a mean of 5 varieties, the answer is probably to recombine genotypes to obtain the seed size of the varieties such as Rigasol or AllstarRM, with the seed number, and high oil content, of DK3790 or HeliasolRM, for example. It has been suggested [9] that the best yields probably come from genotypes with medium seed numbers and medium seed sizes. What constitutes ?medium? has changed over the years, but it means that breeding for yield cannot concentrate on only one of these characters, but requires an equilibrium between the two.

The last variety of the first generation, the first cytoplasmic hybrid Relax, could, by its yield, be have included in group 2, except for a factor not studied in these trials: downy mildew resistance. Downy mildew first appeared in France in 1962 and when breeding started resistance was immediately necessary. The first hybrid resistant to downy mildew was Rémil, but the yield of this variety, and its resistance to lodging, were insufficient. Relax was not downy mildew resistant so its development was limited and the extension of the sunflower crop from 30000 ha to more than 300000 ha came with the registration of the first cytoplasmic downy mildew resistant hybrids Mirasol and Primasol in 1977 and 1978. Since then, varieties have been bred, or converted by back cross, for resistance to most or all French races of downy mildew, and the varieties widely grown at any period have always had the necessary resistances. Although downy mildew isolates resistant to metalaxyl treatment are found quite widely [10], the treatment applied for the present study gave satisfactory protection of the older varieties, with no significant downy mildew symptoms in the trials.

Concerning Phomopsis and Sclerotinia resistance, the analysis in table 4 indicates that, for this series of trials, disease resistance intervened for about $25 \%$ of the yield gain (group 4 with disease: 147.4, without disease 136.6), but it must be remembered that this result is dependant on the intensity of disease attack in this particular series of trials. What is striking is that the ranking of varieties, in trials with or without disease, is completely stable for those in group 4, whereas some older varieties changed order by more than one place: in the presence of Sclerotinia/Phomopsis: Rémil: +2 and Frankasol +3 but Cargisol -2 and Vidoc -6 (data not shown). The apparent difference in reduction in 
disease attack between Sclerotinia and Phomopsis may in part be due to the fact that there has been selection for resistance to Sclerotinia since 1970 whereas selection for resistance to Phomopsis only started in 1984. However, it is generally considered that improvement in resistance to Phomopsis has been rapid [11] and the difference may also be explained by the level of attack observed: for Sclerotinia, mean percentage attack of the four groups varied from $27 \%$ to $10 \%$, a difference of 17 points, whereas for Phomopsis it varied from $60 \%$ to $38 \%, 22$ points but a much smaller percentage gain in resistance. These trials show that modern sunflower varieties are not completely resistant to either Sclerotinia or Phomopsis but, in most areas where sunflowers are grown, farmers are now unlikely to lose their sunflower crops as a result of these diseases.

The improved disease resistance of recent varieties is at least part of the explanation of why the best relative gains for yield are found in early sown trials and in Central France, since in both cases, potential yield is highest but diseases are more likely to occur [12]. The better relative improvement for yield in the lower yielding trials, may also depend in part on the inclusion of 5 of the 7 trials with disease in this group. It should be noted that, whatever the cropping conditions, recent varieties always give better yields than those registered 10 to 30 years ago. Although modern varieties are now grown more in south west France and Poitou-Charentes than in the Loire Valley and Parisian Basin, if economic factors increased the interest in the sunflower crop in this latter regions, they would be adapted to conditions of higher potential yield.

With the French system of registration on an official Catalogue only of new varieties with oil yields of at least $103 \%$ of the controls, it was quite logical that progress in yield should be observed for genotypes developed over a 30 year period. Thus, the present results are what were expected by sunflower breeders, but contrast with results of Lopez-Pereira et al. [13] in Argentina, who observed an improvement of $23 \%$ for seed yield between open pollinated varieties and hybrids but no difference between sunflower hybrids released between 1983 and 1998. The eight hybrids these authors studied may have been a rather small sample to judge changes in many characters, as they did observe improved disease resistance.

The 1.3\% (33 kg/ha) gain in seed yield per year observed in these sunflower trials is comparable with that obtained for other major field crops. For maize, the most comparable species since also a hybrid crop, results vary from 2.9\% gain in Argentina from 1980-2000 [14] and 2.7\% in Brazil from 19921997 [15] to 0\% in Mexico [16], with many results at 1 to 2\% gain per year (Rumania 1980-1995: 1.1\% [17], Argentina 1979-1991: 105 kg 18], Canada 1959-1988: 1.7\% [19], France 1950-1980: 1.2\% [20]. For self-pollinated crops, the average rate of genetic gain appears to be slightly less, not often exceeding $1 \%$ per year, for example for wheat and other cereals: Croatia 1954-1985: 0.88\% [21], U.K. 1948-1998: 110 kg [22], Norway 1957-1988: winter wheat 50 kg, spring wheat: 35 kg, barley: 28 kg [23], Moldavia 1957-1988: 80 kg [24]. Similarly, for soybean, in India, Karmakar and Bhatnagar [25] reported a gain of $22 \mathrm{~kg} /$ year comparing varieties released between 1969 and 1993, in Thailand, Sarobol and Vichukit [26] reported $13.2 \mathrm{~kg}$ /year between 1965 and 1987 and in the USA, for 19241980, Specht and Williams [27] $12.5 \mathrm{~kg} /$ year. For all these crops, as for sunflower, many authors reported an improvement in resistance to diseases or lodging, giving improved yield stability. 


\section{CONCLUSION}

In conclusion, the present study has shown that sunflower breeding programmes for varieties adapted to France have given continuous improvement in spite of variable economic interest and support for this crop. The results indicate that there is no reason to doubt that further improvements in potential yield will be obtained in the future, the success of the sunflower crop in France, and more generally in Europe, will depend to a large extent on economic factors.

Acknowledgements We would like to thank all the companies, research centres and farmers who supported or undertook the trials: Advanta, Agri-Obtentions, Astria, Caussade Semences, CETIOM En Crambade, CETIOM Saint-Florent, Cultivance, INRA Clermont-Ferrand, INRA Lusignan, INRA Toulouse, Maïsadour, Monsanto, Pioneer Génétique, R.A.G.T., Soltis, Syngenta and Verneuil. Promosol provided some general support of this programme.

\section{REFERENCES}

1 - Leclercq P. Une stérilité mâle utilisable pour la production d'hybrides simples de tournesol. Ann Amélior PI 1966 ; 18 : 307-15.

2 - Leclercq P. Une stérilité mâle cytoplasmique chez le tournesol. Ann Amélior Pll $1969 ; 19$ : 99-106.

3 - Leclercq D. Marges : Le tournesol grand gagnant en 1989. Cultivarl $1990 ; 269$ : 108-9.

4 - Vear F,Tourvieille D. Le jugement des hybrides de tournesol vis-à-vis de l'infection naturelle des capitules par Sclerotinia sclerotiorum. Inf. Tech. CETIOMI 1987 ; 99 : 9-14.

5 - Viguie A, Serre F, Walser P, Vear F, Tourvieille de Labrouhe D. The use of natural infections under controlled conditions and of artificial infections to estimate phomopsis resistance of sunflower hybrids: conclusions after ten years of trials. Proc. $15^{\text {th }}$ Int. Sunflower Conf., Toulouse, France, $12-$ 16/06/2000I 2000 ; K78-K83.

6 - Pilorge E. Tournesol et produits phytosanitaires : état des lieux. Rencontres Annuelles du CETIOM 7/12/1999. Ed CETIOM, 12 av. George V, 75005 Paris 1999 ; 23-7.

7 - Reau R, Wagner D. Tournesol, azote et environnement. Rencontres Annuelles du CETIOM 7/12/1999. Ed CETIOM, 12 ave George V, 75005 Paris ; 17-9.

8 - Fick GN (1975). Heritability of oil content in sunflowers. Crop Scil $1999 ; 15: 77-8$. 
9 - Triboi-Blondel AM. Productivité du tournesol, Compte-rendu 2001 : expérimentation de Clermond-Ferrand. Rpt Activité Promosol 2001, ed. : AMSOL, 17, rue du Louvre, 75002 Paris 2002 ; Chap 2.1, 17 pp.

10 - Albourie JM, Tourvieille J, Tourvieille de Labrouhe D. Resistance to metalaxyl in isolates of the sunflower pathogen Plasmopara halstedii. Eur J Plant Patholl $1998 ; 104$ : 235-42.

11 - Penaud A, Jouffret P. Phomopsis du tournesol : la protection fongicide se raisonne. CETIOMOléoscopel $1996 ; 33: 27-9$.

12 - Lagarde F. La campagne tournesol 2001 gâchée par les excès d'eau et les maladies. CETIOMOléoscopel $2001 ; 64: 27-8$.

13 - Lopez-Pereira M, Sadras VO, Trapani N. Genetic improvement of sunflower in Argentina between 1930 and 1995. Field crops Researchl $1999 ; 62: 157-66$.

14 - Eyherabide GH, Damilano AL. Comparison of genetic gain for grain yield of maize between the 1980s and 1990s in Argentina. Maydical $2001 ; 46: 277-81$.

15 - Alliprandini LF, Duarte AP, Kanthack RAD. Genetic gain in commercial maize in summer and autumn-winter crops in the Paranapanema River Valley, Brasil, 1992 to 1997. Maydical 1998 ; 43 : 5564.

16 - Moran Rosas V, Ramirez Diaz JL, Parra JR. Genetic gain of improved maize varieties released in different years. Revista Fitotechnia Mexicanal $1993 ; 16$ : 102-12.

17 - Ciocazanu I, Cosmin O, Sarca T, Bica N, Bagiu C. Genetic gain in maize breeding program-mes from RICIC-Fundulea in the last two decades. Anale ICPCP Funduleal $1998 ; 65: 55-87$.

18 - Eyherabide GH, Damilano AL, Colazo JC. Genetic gain for grain yield of maize in Argentina. Maydical $1994 ; 39$ : 207-11.

19 - Tollenaar M. Genetic improvement in grain yield of commercial grain hybrids grown in Ontario from 1959 to 1988 . Crop Scil $1989 ; 29: 1365-71$.

20 - Derieux M, Darrigrand M, Gallais A, Barrière Y, Bloc D, Montalent Y. Estimation du progrès génétique réalisé chez le maïs grain en France entre 1950 et 1985 . Agronomiel $1987 ; 7: 1$-11. 
21 - Novoselovic D, Drezner G, Lalic A. Contribution of wheat breeding to increased yields in Croatia from 1954 to 1985. Cereal Research Communicationsl $2000 ; 28$ : 95-9.

22 - Austin RB. Yield of wheat in the united Kingdom: recent advances and prospects. Crop Scil 1999 ; 39 : 1604-10.

23 - Strand E. Yield progress and the sources of yield progress in Norwegian small grain production 1960-92. Norsk Landbruksforskingl 1994 ; 8 : 111-26.

24 - Anghel I, Rusanovischi G, Ciolpan G (.) Genetic progress achieved in winter bread wheat breeding at the Podu-Iloaiei Agricultural Research Station (1957-1988). Cercetari Agronomice in Moldavial $1990 ; 23: 23-9$.

25 - Karmakar PG, Bhatnagatr PS. Genetic improvement of soybean varieties released in India from 1969 to 1993. Euphytical 1996 ; 90 : 95-103.

26 - Sarobol E, Vichukit V. Genetic contributions of Thai soybean cultivars to annual yield increases. The Kasetsart Journal: Natural Sciencesl $1991 ; 25$ : 127-32.

27 - Specht JE, Williams JH. Contribution of genetic technology to soybean productivity retrospect and prospect. Proc Symposium Crop Sci Soc USA Special Publicationl $1984 ; 7$ : 49-74. 


\section{Illustrations}

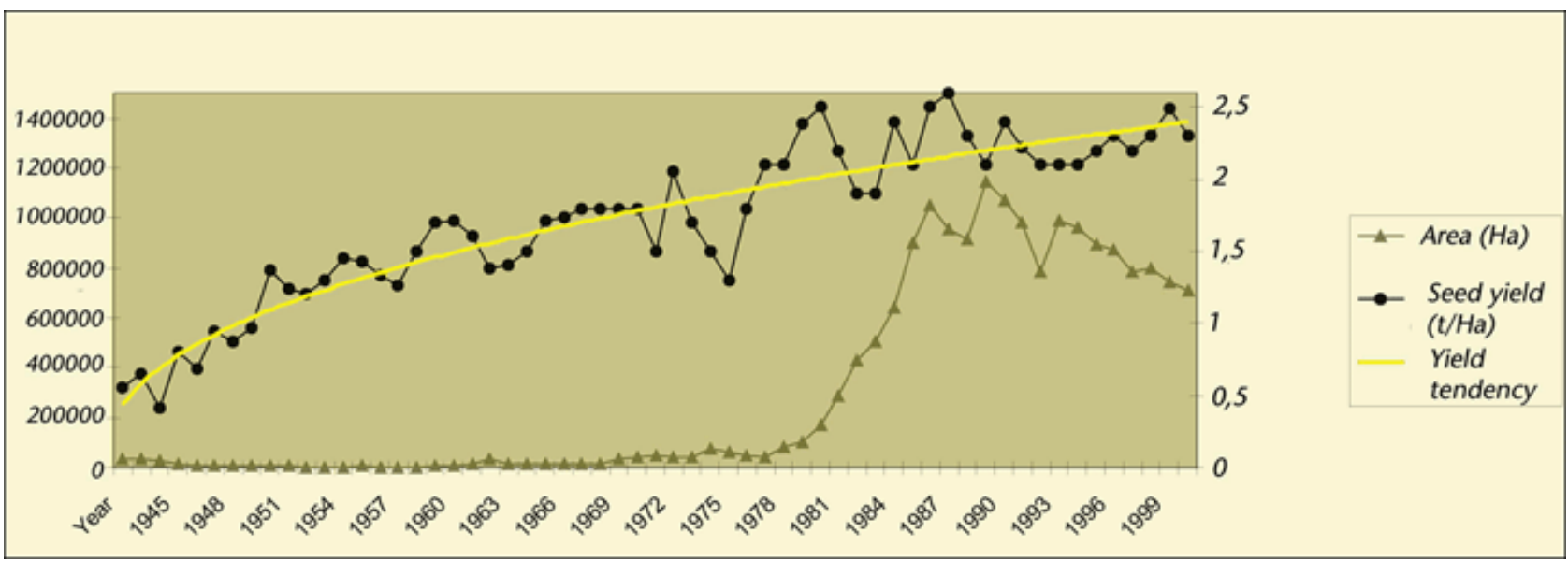

Figure 1 - The area of sunflowers grown in France and national average sunflower yields since 1943 (source SCEES).

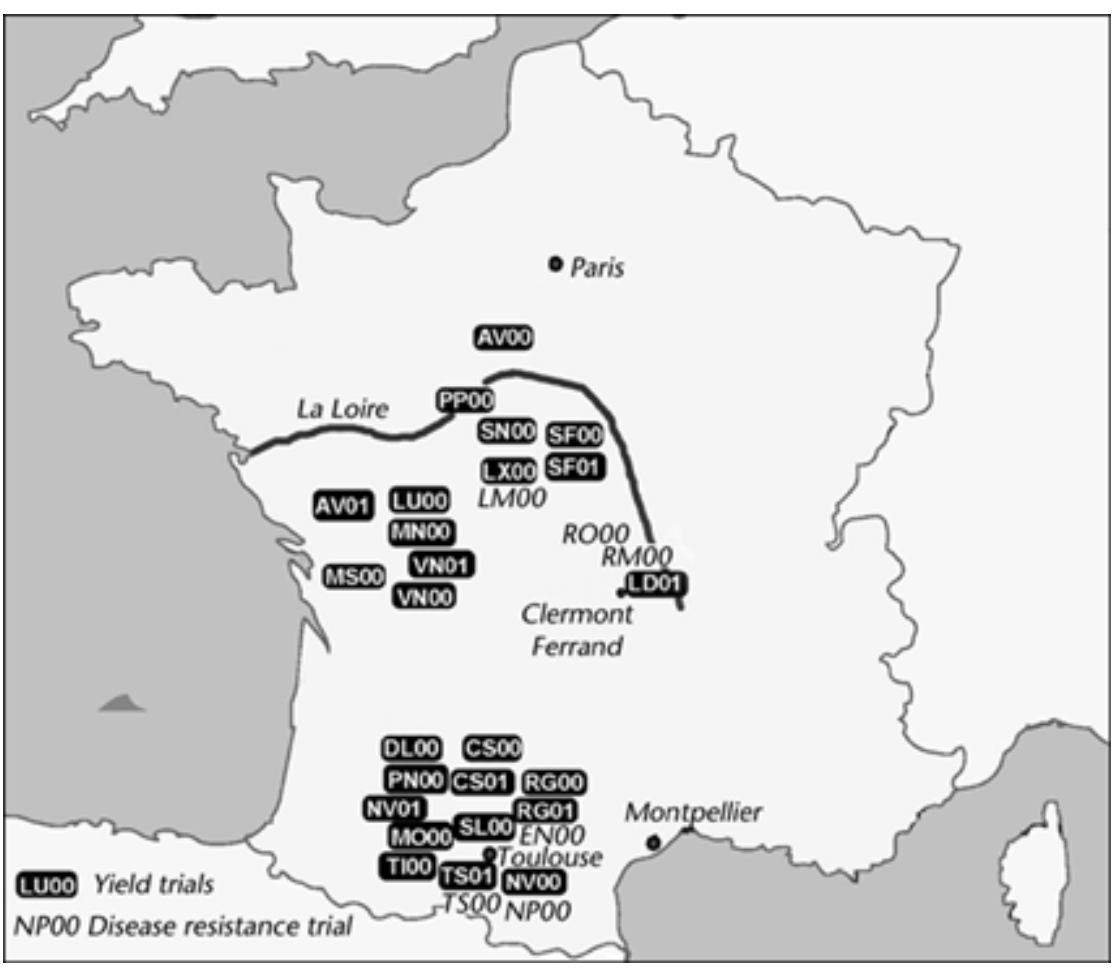

Figure 2 - Locations of sunflower yield and disease resistance trials in 2000 and 2001. 


\begin{tabular}{|c|c|c|c|c|}
\hline Name & Breeder & & First year grown & Special character \\
\hline 1. Peredovik & V.N.I.I.M.K., Russia & & 1960 & Open pollinated variety \\
\hline 2. INRA 6501 & I.N.R.A, France & & 1970 & First hybrid with genic male sterility \\
\hline 3. Rémil & I.N.R.A, France & & 1974 & First downy mildew resistant hybrid \\
\hline 4. Airelle & I.N.R.A., France & & 1973 & \\
\hline 5. Relax & IN.R.A., France & & 1975 & First hybrid with cyoplasmic male sterility \\
\hline 6. Mirasol & Semences Cargill, Franc/U.S.A. & . & 1978 & First CMS downy mildew resistant hybrid \\
\hline 7. Primasol & I.N.RA./C.S.T., France & & 1979 & CMS, very early \\
\hline 8. Cargisol & Semences Cargilt, France/U.S.A. & & 1983 & \\
\hline 9. Viki & Maisadour, France/C.K.I., Hungary & & 1984 & \\
\hline 10. Frankasol & Semences Cargill, France/U.S.A. & & 1984 & \\
\hline 11. Abena & Prograin Génétique, France/l.W.S., Bulgaria & & 1988 & \\
\hline 12. Vidoc & Maisadour, France/G.K.I., Hungary & & 1989 & Susceptible to Sclerotinia/flower bud \\
\hline 13. Euroflor & Rustica Semences, France/Sigco, U.S.A. & & 1988 & Late \\
\hline 14. Santiago & Hilleshög-NK, France/L.C.C.P.T., Rumania & & 1993 & \\
\hline 15. DK3790 & R.A.G.T, France/C.K.I., Hungary/Dekalb, U.S.A. & & 1994 & \\
\hline 16. Rigasol & Semences Cargill, France & & 1995 & \\
\hline 17. Melody & Hillesdhög-NK, France & & 1996 & \\
\hline 18. LCS660 & Limagrain Genetics, France & & 1998 & \\
\hline 19. AllstarRM & Rustica-Prograin Génétique, France/l.W.S, Bulgaria & & 1999 & \\
\hline 20. HeliasolRM & S.D.M.E., France /K.W.S., Germany & - & 2000 & \\
\hline
\end{tabular}

Table 1 - Varieties used in the study of sunflower breeding 1970-2000.

\begin{tabular}{|c|c|c|c|c|c|c|c|c|c|c|}
\hline & $\begin{array}{l}\text { Grain } \\
\text { Yield }\end{array}$ & $\begin{array}{c}\text { Oil } \\
\text { Content }\end{array}$ & Oil Yield & $\begin{array}{c}\% \\
\text { Humidity }\end{array}$ & $\begin{array}{c}1000 \text { Seed } \\
\text { wt. }\end{array}$ & $\begin{array}{l}\text { Number } \\
\text { Grain/m }\end{array}$ & $\begin{array}{c}\text { Plant } \\
\text { Height }\end{array}$ & $\%$ lodging & $\begin{array}{c}\% \\
\text { Sclerotinia }\end{array}$ & $\begin{array}{c}\% \\
\text { Phomopsis }\end{array}$ \\
\hline 1. Peredovik & 92.2 & 105.4 & 97.2 & 101.4 & 108.6 & 84.9 & 108.0 & 185.7 & 94.5 & 97.9 \\
\hline 2. INRA 6501 & 100.4 & 94.0 & 94.2 & 99.1 & 84.6 & 109.0 & 92.1 & 70.1 & 161.8 & 87.4 \\
\hline 3. Rémil & 99.2 & 100.8 & 100.0 & 107.4 & 109.2 & 90.8 & 112.9 & 132.9 & 66.1 & 117.4 \\
\hline 4. Airelle & 96.1 & 100.5 & 95.6 & 92.9 & 91.2 & 105.4 & 91.4 & 97.7 & 132.2 & 108.1 \\
\hline 5. Relax & 111.9 & 99.2 & 111.0 & 99.2 & 106.5 & 105.1 & 95.6 & 13.7 & 45.3 & 89.5 \\
\hline 6. Mirasol & 110.1 & 104.8 & 115.3 & 94.7 & 80.8 & 136.3 & 102.8 & 62.3 & 70.3 & 106.3 \\
\hline 7. Primasol & 98.9 & 105.2 & 104.0 & 70.5 & 78.1 & 126.6 & 89.4 & 134.8 & 198.0 & 86.6 \\
\hline 8. Cargisol & 117.0 & 109.9 & 128.7 & 102.8 & 92.8 & 126.1 & 101.4 & 13.7 & 67.0 & 94.6 \\
\hline 9. Viki & 122.9 & 108.9 & 133.9 & 110.9 & 83.9 & 146.5 & 98.3 & 13.7 & 94.8 & 92.3 \\
\hline 10. Frankasol & 114.3 & 101.4 & 115.9 & 79.5 & 100.3 & 114.0 & 101.4 & 65.2 & 43.5 & 97.0 \\
\hline 11. Albena & 119.0 & 104.2 & 124.1 & 77.8 & 97.6 & 121.9 & 101.9 & 45.4 & so. 3 & 69.5 \\
\hline 12. Vidoc & 109.2 & 101.6 & 111.0 & 87.9 & 103.1 & 105.9 & 105.0 & 42.9 & 62.5 & 124.1 \\
\hline 13. Euroflor & 128.1 & 105.8 & 135.5 & 143.1 & 89.8 & 142.7 & 103.5 & 36.9 & 71.8 & 56.3 \\
\hline 14. Santiago & 121.0 & 109.5 & 132.4 & 103.0 & 102.7 & 117.8 & 93.1 & 31.4 & 50.8 & 50.0 \\
\hline 15. DK3790 & 124.3 & 111.8 & 138.9 & 83.2 & 76.1 & 163.3 & 90.2 & 18.4 & 61.0 & 80.1 \\
\hline 16. Rigasol & 137.9 & 103.9 & 143.2 & 81.4 & 127.7 & 108.0 & 102.2 & 20.6 & 10.3 & 44.0 \\
\hline 17. Melody & 152.1 & 102.9 & 156.5 & 124.4 & 105.3 & 144.0 & 109.1 & 13.7 & 60.0 & 63.0 \\
\hline 18. LC5660 & 144.5 & 105.1 & 151.9 & 105.0 & 95.5 & 151.3 & 105.5 & 44.1 & 48.5 & 86.0 \\
\hline 19. AlstarRM & 132.0 & 105.4 & 139.1 & 85.0 & 111.9 & 118.0 & 99.5 & 22.4 & 33.7 & 58.0 \\
\hline 20. HeliasolRM & 132.8 & 111.8 & 147.2 & 102.3 & 92.5 & 143.6 & 85.8 & 23.0 & 29.0 & 67.5 \\
\hline Number of results & 25 & 24 & 24 & 14 & 4 & 4 & 21 & 2 & 4 & 8 \\
\hline First group mean & 2.54 tha & $43.1 \%$ & $1.09 \mathrm{t} / \mathrm{ha}$ & $10.5 \%$ & $52.2 \mathrm{~g}$ & 4866 & $149 \mathrm{~cm}$ & $25.2 \%$ & $27.2 \%$ & $60.4 \%$ \\
\hline
\end{tabular}

Table 2 - Mean results for each variety in trials in 2000 and 2001 as percentages of the means of the first group of five varieties. 


\begin{tabular}{|lrrrr|}
\hline & Group 1 & Group 2 & Group 3 & Group 4 \\
\hline Varietal Characters & & & & \\
Grain Yield & 100 & 112.7 & 120.3 & 139.9 \\
Oil Yield & 100 & 119.6 & 128.4 & 147.6 \\
Oil Content & 100 & 106.0 & 106.6 & 105.8 \\
1000 seed wt & 100 & 81.2 & 93.9 & 106.6 \\
Seed nb/m ${ }^{2}$ & 100 & 129.2 & 128.2 & 131.0 \\
\% humidity & 100 & 94.7 & 98.8 & 99.6 \\
Height & 100 & 98.7 & 98.8 & 100.4 \\
\% lodging & 100 & 57.9 & 35.0 & 24.7 \\
\% Sclerotinia head rot & 100 & 94.7 & 59.3 & 36.3 \\
\% Phomopsis & 100 & 95.4 & 76.0 & 63.7 \\
\hline
\end{tabular}

Table 3 - Means of each group of sunflower varieties as percentages of the first group.

\begin{tabular}{|c|c|c|c|c|c|c|c|}
\hline \multirow{3}{*}{$\begin{array}{l}\text { Sowing Date } \\
\text { Mean yield }\end{array}$} & \multirow[t]{3}{*}{ Region } & \multirow{2}{*}{\multicolumn{2}{|c|}{ early }} & \multirow{2}{*}{\multicolumn{2}{|c|}{ medium }} & \multirow{2}{*}{\multicolumn{2}{|c|}{ late }} \\
\hline & & & & & & & \\
\hline & & $>3 \mathrm{t} / \mathrm{ha}$ & $<3 \mathrm{t} / \mathrm{ha}$ & $>3 \mathrm{t} / \mathrm{ha}$ & $<3 t / h a$ & $>3 \mathrm{t} / \mathrm{ha}$ & $<3 \mathrm{t} / \mathrm{ha}$ \\
\hline \multirow{5}{*}{$\begin{array}{l}\text { Without } \\
\text { Disease }\end{array}$} & Central France & & LDO1 & AVOO & LX00 & & SF01 \\
\hline & Poitou-Charente & MSO0 & & LUoO & MNOO & & VNoO \\
\hline & & & & AV01 & & & VN01 \\
\hline & South-West & NVOO & NV01 & RC00 & RCO1 & $\mathrm{Cs} 00$ & \\
\hline & & & TS01 & DLO0 & SFOO & & SNOO \\
\hline \multirow{2}{*}{$\begin{array}{l}\text { With } \\
\text { Disease }\end{array}$} & Central France & & $P 00$ & & & & \\
\hline & South-West & $s L 00$ & $\pi 00$ & PNOO & & & MO00 \\
\hline
\end{tabular}

Table 4 - Cropping conditions for each of the individual yield trials. The trial initials are those shown on the map in figure 2.

Year: $00=2000$ and $01=2001$. 


\begin{tabular}{|c|c|c|c|c|c|c|}
\hline & \multirow[t]{2}{*}{ Number of results } & \multirow[t]{2}{*}{ Group 1} & \multirow[t]{2}{*}{ Group 2} & \multicolumn{2}{|c|}{ Group 3} & \multirow[t]{2}{*}{ Group 4} \\
\hline & & & & with Vidoc & without Vidoc & \\
\hline \multicolumn{7}{|l|}{ Year } \\
\hline 2000 & 17 & 2.7 tha $(I)$ & 111.4 & 119.4 & 122.5 & 139.4 \\
\hline 2001 & 8 & 2.3 tha (2) & 114.2 & 122.6 & 124.8 & 140.0 \\
\hline t-test & \multicolumn{6}{|c|}{$1 / 2=1.21 \mathrm{~ns}$} \\
\hline \multicolumn{7}{|c|}{ Presence/Absence moderate attack by Sclerotinia/Phomopsis } \\
\hline With disease & 7 & $2.4 \mathrm{t} /$ ha $(3)$ & 115.3 & 122.2 & 128.5 & 147.4 \\
\hline Without disease & 18 & $2.6 \mathrm{t} / \mathrm{ha}(4)$ & 111.3 & 119.6 & 121.0 & 136.6 \\
\hline Difference & & & $4.0 \%$ & $2.6 \%$ & $7.5 \%$ & $10.8 \%$ \\
\hline t-test & \multicolumn{6}{|c|}{$3 / 4=0.85 \mathrm{~ns}$} \\
\hline \multicolumn{7}{|l|}{ Sowing date } \\
\hline Early & 8 & 2.5 tha (S) & 114.1 & 121.9 & 126.1 & 151.4 \\
\hline Medium & 9 & $2.8 \mathrm{t} / \mathrm{ha}(6)$ & 109.2 & 116.1 & 117.3 & 129.0 \\
\hline Late & 7 & $2.2 \mathrm{t} / \mathrm{ha}(7)$ & 115.5 & 125.1 & 126.3 & 143.0 \\
\hline t-test & \multicolumn{6}{|c|}{$5 / 6=1.43 \mathrm{~ns} ; 5 / 7=0.88 \mathrm{~ns} ; 6 / 7=1.88 \mathrm{~ns}$} \\
\hline \multicolumn{7}{|l|}{ Region of France } \\
\hline Centre & 7 & 2.3 tha (8) & 113.5 & 122.8 & 126.7 & 142.0 \\
\hline Poitou/Charentes & 6 & 2.5 tha (9) & 108.5 & 119.7 & 120.7 & 136.7 \\
\hline South-West & 12 & 2.8 t/ha $(10)$ & 113.8 & 119.4 & 123.9 & 139.8 \\
\hline t-test & \multicolumn{6}{|c|}{$8 / 9=0.64 \mathrm{~ns} ; 8 / 10=1.68 \mathrm{~ns} ; 9 / 10=0.83 \mathrm{~ns}$} \\
\hline \multicolumn{7}{|l|}{ Yield level } \\
\hline Mean $<3.0$ tha & 14 & 2.1 tha (11) & 111.9 & 121.6 & 124.5 & 144.0 \\
\hline Mean $>3.0 t / h a$ & 11 & 3.1 tha (12) & 111.4 & 117.7 & 120.2 & 134.0 \\
\hline t-test & \multicolumn{6}{|c|}{$11 / 12=5.90^{* *}$} \\
\hline
\end{tabular}

Table 5 - Seed yield according to cropping conditions for each group of 5 sunflower varieties as a percentage of the first group. 